Ricardo Sharon (Orcid ID: 0000-0003-1724-3669)

\title{
Percutaneous intrarenal transplantation of differentiated induced pluripotent stem cells into newborn mice
}

\author{
${ }^{1}$ Ricky W. K. Lau, ${ }^{1}$ Ali Al-Rubaie, ${ }^{1}$ Sheetal Saini, ${ }^{1}$ Andrea F. Wise and ${ }^{1}$ Sharon D. Ricardo \\ ${ }^{1}$ Department of Anatomy and Developmental Biology, Biomedical Discovery Institute, Monash \\ University, Clayton Victoria 3800, Australia
}

Corresponding author:

Professor Sharon D. Ricardo

Biomedical Discovery Institute

15 Innovation Walk

Monash University

Clayton, Victoria 3800

Australia

E-mail: sharon.ricardo@monash.edu

Phone: +6139905 0671

This is the author manuscript accepted for publication and has undergone full peer review but has not been through the copyediting, typesetting, pagination and proofreading process, which may lead to differences between this version and the Version of Record. Please cite this article as doi: $10.1002 / a r .24371$

This article is protected by copyright. All rights reserved. 


\begin{abstract}
The in vivo engraftment of induced pluripotent stem cell (iPSC)-derived podocytes following allogeneic transplantation into host kidneys remains a challenge. Here we investigate the survival and engraftment of human dermal fibroblasts-derived differentiated iPSCs using a newborn mouse model, which represents a receptive immuno-privileged host environment. iPSCs were generated from skin biopsies of patients using Sendai virus reprogramming. Differentiation of nephrin (NPHS1)-green fluorescent protein (GFP) iPSCs into kidney podocytes (iPSC-PODs) was performed by the addition of Activin A, bone morphogenetic protein 7 (BMP7) and retinoic acid over 10 days of culture. To assess the in vivo incorporation of cells, undifferentiated iPSCs or day 10 iPSC-PODs, were labelled with either carboxyfluorescein succinimidyl ester (CFSE) or Qdot nanocrystals (Q705). Thereafter, $1 \times 10^{5}$ differentiated iPSC-PODs were injected directly into the kidneys of mouse pups at postnatal day one (P1). Using co-expression analysis of glomerular and podocyte-specific markers, Day 10 differentiated iPSC-PODs that were positive for podocin, were detected following direct kidney injection into newborn mice up to one week after transplantation. Undifferentiated iPSC-PODs were not detected at the same timepoint. The transplanted cells were viable and located in the outer nephrogenic zone where they were found to co-localise with, or sit adjacent to, cells positive for glomerular-specific markers including podocin, synaptopodin and Wilms' tumour 1 (WT1). This study provides proof-of-principle that transplanted iPSC-POD can survive in recipient newborn mouse kidneys due to the immature and immunoprivileged nature of the developing postnatal kidneys.
\end{abstract}

This article is protected by copyright. All rights reserved. 


\section{Introduction}

Chronic kidney disease (CKD) is a major and growing public health concern with increasing incidence and prevalence worldwide (Afkarian et al., 2013). With $10 \%$ of the world's population suffering from CKD, it continues to be a major challenge for global health. For many patients, CKD progresses to end-stage renal disease leaving renal replacement therapy, which includes dialysis or kidney transplantation, as the only treatment option.

Mesenchymal stem cells (MSCs) have afforded promise for cell therapy in the treatment of numerous immune and non-immune diseases over the last decade (Peired, Sisti, \& Romagnani, 2016). However, a challenge exists due to limited cell survival post-transplantation due, in part, to the inflammatory microenvironment and immune rejection. Autologous MSC transplantation has been extensively studied in experimental models in cats (Quimby et al., 2016), sheep (Behr et al., 2009), monkeys (Moghadasali et al., 2014) and rodents (Kunter et al., 2006). However, improvement in kidney histology and function following MSC transplantation is mediated by paracrine factors that promote endogenous tissue regeneration and reduce inflammation (Peired et al., 2016). The true beneficial effect of cell therapy ultimately depends on the number of administered cells reaching the target tissue, their viability, and their ability to promote tissue regeneration (McFetridge, Del Borgo, Aguilar, \& Ricardo, 2018).

In contrast, since their discovery (Takahashi et al., 2007) induced pluripotent stem cells (iPSCs) have been considered a viable cell source for endogenous cell replacement following autologous transplantation. Patient-derived iPSCs can generate kidney cells that preserve crucial genotypephenotype correlations. As such, iPSCs may provide a valuable tool to develop disease modelling, for understanding how mutations cause disease, for screening new drugs, and potentially to test for autologous cell-replacement therapies.

A range of kidney cell types, differentiated from iPSCs, have been tested in experimental kidney disease models to assess cell survival and possibly integration following transplantation. Human 
iPSCs differentiated into renal progenitor cells were transplanted intravenously into adult nonobese diabetic/severe combined immunodeficiency (NOD-SCID) mice with acute kidney injury, induced by cisplastin (Imberti et al., 2015). The iPSCs, labelled with the red fluorescent cell tracker, PKH26, showed engraftment into mouse tubular structures (Imberti et al., 2015). Improvement in kidney function and restoration of kidney structure were observed using differentiated-iPSCs, but not following the injection of undifferentiated iPSCs. Another study reported similar findings, with an embryoid-body based differentiation approach where iPSCs were differentiated into proximal tubular like cell aggregates (Toyohara et al., 2015). The study involved the differentiation of a double knock-in reporter cell line, with two key kidney developmental markers, Sine Oculis Homeobox Homolog 2 (Six2) and Odd-skipped related 1 (Osr1), into renal progenitor cell aggregates, followed by transplantation under the kidney capsule into immunodeficient mice (NOD.CB17-Prkdc ${ }^{\mathrm{sid} / J}$ ). The key difference between the two studies was that the second study did not conclude any cell integration into the host kidney.

While there are different administration options for cell transplantation in animals, such as intravenous (i.v.) versus intraperitoneal (i.p.) injection (Turner, Brabb, Pekow, \& Vasbinder, 2011), these routes do not directly target the kidney and therefore are not ideal for the detection of a pluripotent cell progeny, where the cells lack the ability to home to the site of injury. Considerations in developing iPSCs for cell replacement therapy are the source of the therapeutic cells and the immunological consequences following transplantation. Delivering immunematched autologous iPSC differentiated derivatives should eliminate the detrimental effects of lifelong immunosuppression needed after most allogeneic human transplants. In the experimental setting, while immunodeficient or humanised mice have been used for the majority of allogeneic iPSC transplantation studies (Bantounas et al., 2018; Imberti et al., 2015; Sharmin et al., 2016; Toyohara et al., 2015; van den Berg et al., 2018), there remains intense debate if iPSC-derived derivatives induce a T cell immune response (Garreta, Sanchez, Lajara, Montserrat, \& Belmonte, 2018). 
Newborn mice are an ideal recipient of iPSCs as they serve as an immunocompromised host. Additionally, newborn mice continue nephron development for up to approximately one week postpartum, and thereby provide an ideal developmental microenvironment that allows for cell engraftment and in vivo differentiation (Hartman, Lai, \& Patterson, 2007). Newborn mouse recipients may thereby be ideal for the transplantation of iPSC-kidney cells, in order to assess viability and survival during this nephrogenic regenerative window.

The aim of the study was to develop a cell transplantation model to track cells and test for viability after direct injection into kidneys. Kidney podocytes generated from iPSCs were differentiated using monolayer cultures, prior to transplantation into newborn mouse kidneys. Differentiation of iPSCs into podocytes (iPSC-POD), over 10 days of in vitro culture, was performed using NPHS1 (encoding for nephrin)-green fluorescent protein (GFP) iPSCs by the addition of activin A, bone morphogenetic protein 7 (BMP7) and retinoic acid. To assess in vivo cell survival, iPSC-PODs were labelled with either carboxyfluorescein succinimidyl ester (CFSE) or a cell tracker (endocytosed Qdot crystals). Thereafter, $1 \times 10^{5}$ of differentiated iPSCPODs were directly injected into the kidneys of mouse pups at postnatal day one (P1) using a novel intrarenal administration technique to achieve direct cell transplantation. A time course analysis of the detection of differentiated iPSC-PODs in recipient kidneys was compared to undifferentiated cells, using confocal fluorescence microscopy using the co-expression of podocyte markers.

This article is protected by copyright. All rights reserved. 


\section{Methodology}

\section{iPSC culture}

iPSCs were reprogrammed from dermal skin fibroblasts obtained from a healthy individual using a CytoTune $^{\mathrm{TM}}$ iPS 2.0 Sendai Reprogramming Kit (Invitrogen) under informed consent from the Melbourne Health Human Research and Ethics Committee, Royal Melbourne Hospital, Australia. A NPHS1-GFP iPSC reporter cell line, expressing nephrin-GFP protein associated podocyte specific expression, was also used (Sharmin et al., 2016). NPHS1 encodes for nephrin an immunoglobulin G (IgG)-like protein, which is important for the integrity of the slit diaphragm (Huber, Kottgen, Schilling, Walz, \& Benzing, 2001). Control iPSCs and NPHS1GFP-iPSCs were initially grown on an irradiated mouse embryonic fibroblasts (MEFs) feeder layer, in Dulbecco's Modified Eagle Medium: Nutrient mixture F-12 (DMEM/F12; Gibco ${ }^{\mathrm{TM}}$, Life Technologies) containing 20\% KnockOut $^{\mathrm{TM}}$ serum replacement (KOSR; Gibco ${ }^{\mathrm{TM}}$ ) and 10 mM Non-Essential Amino Acids (NEAA; Gibco ${ }^{\mathrm{TM}}$ ) supplemented with $10 \mathrm{ng} / \mathrm{ml}$ basic fibroblast growth factor (b-FGF). Following culture of iPSC colonies on a feeder free system using Geltrex ${ }^{\mathrm{TM}}$ (Gibco $^{\mathrm{TM}}$, A1413201), the addition of 10ng/ $\mu$ l b-FGF was found to increase survivability, and culture on laminin-E8 enhanced podocyte attachment (data not shown), which has been reported previously (Musah et al., 2017). After one week, iPSCs were transferred to a non-feeder platform on a T25 cell culture flask coated with 1:100 Geltrex ${ }^{\mathrm{TM}}$ substrate (ThermoScientific, A1413202). For routine maintenance, the cells were fed daily with Essential

This article is protected by copyright. All rights reserved. 
8 (E8) medium (Invitrogen), and seeded at 20,000 cells/ $\mathrm{cm}^{2}$ and passaged using StemPro ${ }^{\mathrm{TM}}$ Accutase $^{\mathrm{TM}}$ Cell Dissociation Reagent $\left(\mathrm{Gibco}^{\mathrm{TM}}\right.$, A1110501) after five to seven days or when substantial spontaneous differentiation was observed.

\section{Differentiation of iPSCs into podocytes}

Human skin fibroblast-derived iPSCs were differentiated into podocytes using a modified, previously published protocol [Figure 1A; (Song et al., 2012)]. A cocktail of three differentiation factors were used. Activin A which is responsible for initial differentiation into endoderm (Picollet-D’hahan, Dolega, Freida, Martin, \& Gidrol, 2017) and metanephric mesenchyme (Lam, Freedman, \& Bonventre, 2014); and the addition of retinoic acid and bone morphogenetic protein 7 (BMP7), driving factors for the later maturation of the podocytes which are likely to be originated from intermediate mesoderm (Picollet-D’hahan et al., 2017). iPSCs were seeded at 15,000 cells $/ \mathrm{cm}^{2}$ and the differentiation factors added when cells were 50-60\% confluent using DMEM/F12 + GlutaMAX ${ }^{\mathrm{TM}}$ media supplemented with 2-Mercaptoethanol (Gibco ${ }^{\mathrm{TM}}$, 21985023), 10 mM NEAA, penicillin (100 U/ml)/streptomycin (100 $\mu \mathrm{g} / \mathrm{ml}$; Gibco $\left.{ }^{\mathrm{TM}}\right)$ and 10\% foetal bovine serum (FBS). Podocyte differentiation was induced with the addition of $50 \mu \mathrm{g} / \mathrm{ml}$ Activin A (Peprotech, 120-14E-100), $100 \mu \mathrm{g} / \mathrm{ml}$ BMP7 (Peprotech) and $1 \mathrm{mM}$ retinoic acid (SigmaAldrich). The cells were split 1:2 after the first day of differentiation. After 10 days, the growth factors were removed and the iPSC-PODs were maintained in DMEM/F12 medium with media replacement every second day.

This article is protected by copyright. All rights reserved. 


\section{Cell culture of immortalised podocytes (IMM-PODs)}

Human SV40-T transformed immortalised podocytes [IMM-PODs; (Saleem et al., 2002)] were routinely cultured at $33^{\circ} \mathrm{C}$ in Roswell Park Memorial Institute (RPMI) 1640 medium (Gibco ${ }^{\mathrm{TM}}$, 1187503) containing penicillin $(100 \mathrm{U} / \mathrm{ml}) /$ streptomycin $\left(100 \mu \mathrm{g} / \mathrm{ml}\right.$; Gibco $\left.{ }^{\mathrm{TM}}\right), 10 \mu \mathrm{l}$ per $\mathrm{ml}$ Insulin-Transferrin-Selenium (Gibco ${ }^{\mathrm{TM}}$, 4140045) and 10\% FBS. Following splitting, these cells were incubated in the presence of $2 \%$ FBS at $37{ }^{\circ} \mathrm{C}$ for two weeks to reduce proliferation and promote differentiation prior to use.

\section{Immunostaining of iPSC-PODs}

Immunofluorescence analysis was used to visualise podocyte differentiation. The podocytespecific antibodies used were rabbit anti-human polyclonal podocin (Abcam, ab50339) at 1:400 dilution, rat polyclonal IgG Wilms’ tumour 1 antibody (WT1; Santa Cruz Biotechnology, Inc., sc-192) at 1:100 dilution and goat polyclonal IgG synaptopodin antibody (Santa Cruz, P19, sc21537) at 1:200 dilution. For immunofluorescence staining, culture media was removed and cells were washed with phosphate buffered saline (PBS) prior to fixation with 4\% paraformaldehyde (PFA) for 10 minutes. For WT1 staining, the cells were permeabilised with Triton X-100 solution for five minutes at room temperature. A blocking solution consisting of $1 \%$ bovine serum albumin and the animal serum based on the animal species the secondary antibody had

This article is protected by copyright. All rights reserved. 
been raised in was used to stop non-specific staining. After blocking, the cells were washed with PBS three times. Primary antibody was incubated overnight at $4{ }^{\circ} \mathrm{C}$ and on the consecutive day cells were washed three times with PBS before incubation with the secondary antibody for one hour. Cells were then washed three times using PBS and stained with 4', 6-diamidino-2phenylindole (DAPI; Invitrogen ${ }^{\mathrm{TM}}$ ) at a dilution of 1:2000 for 10 minutes at room temperature to visualise cell nuclei. Cells were washed and coverslips were mounted on Superfrost Plus slides using fluorescent mounting medium (DAKO, 53023).

\section{Live cell staining: CFSE and Qdot crystal quenching}

This article is protected by copyright. All rights reserved. 
Prior to transplantation, both non-differentiated and iPSC-PODs were harvested following podocyte differentiation after 10 days of culture. In order to visualise the cells following transplantation into mice, both undifferentiated or iPSC-PODs D10 were stained with either CFSE (carboxyfluorescein succinimidyl ester) Cell Trace ${ }^{\mathrm{TM}}$ Cell Proliferation Kit (Invitrogen, ThermoScientific, C34568) or Qdot Qtracker ${ }^{\mathrm{TM}} 705$ Cell Labelling Kit (Invitrogen, ThermoScientific, Q25061MP) based on the manufacturer's instructions. Both labeling methods of NPHS1-GFP iPSCs were necessary due to the low GFP+ expression of the cells following in vivo transplantation. After dissociation with Accutase ${ }^{\mathrm{TM}}, 1 \times 10^{6}$ of the two cell samples in cell suspension were incubated with the recommended concentration of labelling solution (detailed in the manufacturer's instruction) at $37{ }^{\circ} \mathrm{C}$ for 50 minutes. Cell injection was performed on the same day immediately within an hour after incubation.

\section{Experimental animals and percutaneous intrarenal injection}

Mouse pups at embryonic day 14 (E14) from time-mated pregnant C57BL/6J mice ( $\mathrm{n}=3$ in triplicate experiments) were obtained from the Monash Animal Research Platform (MARP), Monash University, Clayton for acclimatisation prior to pup delivery. The study was conducted and animals were monitored under animal ethics number MARP2015/099 issued by Monash Animal Ethics Committee. Pups were born at term, and the day of birth designated as postnatal day 0 (P0). To inject the left kidney, firm but gentle pressure was applied to the left hind leg. The left kidney was anatomically located inferior to the spleen on the left lateral side of the pup's

This article is protected by copyright. All rights reserved. 
abdomen, which was visible by naked vision upon applied pressure. The needle was injected the tip facing away from the abdomen. Pups were then placed under a heat lamp for at least 15 minutes to recover and to confirm there was no intra-abdominal bleeding. Pups were then returned to their cages. Newborn mice at P1 received either a left intrarenal injection, using an insulin syringe with a $29 \mathrm{G}$ needle (BD Ultra-Fine ${ }^{\mathrm{TM}}$ ), of $1 \times 10^{5}$ iPSC-PODs in $10 \mu \mathrm{l}$ PBS or a control injection of PBS and killed at 1 or 7 days after injection corresponding to postnatal day 2 (P2) or postnatal day 8 (P8).

This article is protected by copyright. All rights reserved. 


\section{Tissue preparation and analysis}

Both the injected and non-injected control kidneys were fixed for two hours in 4\% PFA and immersed in 30\% sucrose overnight. The samples were embedded in optimal cutting temperature (O.C.T; Tissue-Tek®) compound and frozen using isopropanol and dry ice. Frozen kidneys were serial sectioned at $5 \mu \mathrm{m}$ thickness onto Superfrost Plus slides and mounted with a glass coverslip with antifade mounting medium (Vectorshield, H-1000). Every third slide (ie. $1^{\text {st }}, 4^{\text {th }}$ and $7^{\text {th }}$ ) per 50th slides sectioned were mounted and used for visualisation of CFSE+ or q705+ signal. Once confirmed with a positive signal, co-localisation analysis was performed. For glomerular staining, sections were treated with DAKO citrate antigen retrieval at $98{ }^{\circ} \mathrm{C}$ for 30 minutes (performed by Monash Histology Platform). Glomerular structures were stained with the same podocyte-specific antibodies used in the iPSC-PODs characterisation. Cells and tissue sections were visualised using a wide-field microscope (Leica, Dmi8). For higher resolution analysis, a Leica SP8 confocal system was used.

This article is protected by copyright. All rights reserved. 


\section{Results}

\section{Differentiation and characterisation of human iPSCs into the podocyte lineage}

iPSCs reprogrammed from skin fibroblasts were differentiated into podocytes (Figure 1). Differentiated podocytes expressed both podocin and nephrin, as confirmed by immunolabeling. Figure $1 \mathrm{~B}$ shows the expression of cytoplasmic podocin in a localisation pattern radiating from the nucleus and loss of colonisation over the time course of differentiation (D0 to D20). On D15 and D20 of culture, iPSC expansion was still observed despite the cells resembling mature podocytes, with a characteristic flattened morphology compared to the morphological appearance after D5 and D10 of culture. Consequently, the less mature D10 podocytes were chosen for further characterisation and transplantation in vivo. The expression of podocin in differentiated iPSC-POD was found to be analogous to IMM-PODs cultured at $37{ }^{\circ} \mathrm{C}$ (Saleem et al., 2002).

\section{The differentiation of NPHS1-GFP-iPSCs into podocytes}

The reporter iPSC line, NPHS1-GFP-iPSC (Sharmin et al., 2016), was used to visualise the upregulation of nephrin expression in iPSCs differentiating into podocytes. Nephrin expression was observed in the cytoplasm of NPHS1-GFP-iPSC-POD after 10 days of differentiation when cultured on either MEFs or the feeder free substrate, Geltrex ${ }^{\mathrm{TM}}$ (Figure 2A). GFP+ cells that expressed nephrin were found to co-express podocyte-specific markers including synapatopodin

This article is protected by copyright. All rights reserved. 
and WT1 (Figure 2B). Compared to NPHS1-GFP-iPSC, the GFP+ signal was not observed in human IMM-PODs, which was used as a negative control.

\section{Percutaneous intrarenal injection of labelled iPSC-PODs into newborn mice}

A newborn mouse model that enabled direct kidney injection was developed to enable cell tracking of differentiated and undifferentiated iPSCs in vivo. The survival rate of the newborn pups post-injection was 95\%. Two different tracking methods were used to trace the transplanted cells in the newborn kidneys. Two different cell tracking approaches were used, namely, CSFE, a fluorescent cell-staining dye that covalently couples intracellularly, compared to Q705+, which consists of a fluorophore probe that has long-term photostability. A diagrammatic representation of the timeline and experimental analysis is provided in Figure 3, with a detailed description of the experimental technique provided in the methodology section.

\section{iPSC-PODs transplantation into newborn kidneys}

D10 CSFE-labelled iPSC-PODs or undifferentiated iPSCs were administered into newborn mouse kidneys and visualised using immunofluorescence microscopy (Figure 4). CFSE+ cells were found to incorporate into the parenchyma of the host mouse kidneys, which were counterstained with DAPI (Figure 4A). Immunolabelling using podocyte-specific antibodies showed that CFSE+ cells were found in areas of the kidney tubulointerstitium adjacent to glomeruli, which expressed synaptopodin (Figure 4B). CFSE+ cells were also found to integrate

This article is protected by copyright. All rights reserved. 
in developing glomeruli, both co-localising and adjacent to cells that localised for podocin expression (Figure 4C). In addition, CFSE+ transplanted cells were also observed within WT1+ kidney structures resembling renal vesicles but did not show co-localisation (Figure 4D). By higher power confocal microscopy, the CFSE+ cells were confirmed to situate in developing glomeruli of P2 mouse kidneys, suggesting that the transplanted iPSC-PODs were captured in developing glomeruli that expressed synaptopodin and podocin (Figure 4E). Undifferentiated iPSC-PODs were not detected at the same timepoint.

D10 iPSC-PODs were pre-stained with an additional fluorophore used for cell tracing, namely Qdot nonocrystals. The cells adhered normally to the laminin-E8 coated culture flasks (Figure 5A). By P2 Qdot crystal labelled-transplanted cells were found to successfully engraft into newborn kidneys in the nephrogenic zone (Figure 5B). By confocal microscopy, the Q705 vesicles were visualised to in the parenchyma of P2 host kidneys in the nephrogenic zone (Figure 5C). Taking advantage of the brightness and specificity of Qdot crystals, we extended the study to analyse pre-labeled cells that were injected into newborn kidneys and analysed after one week. The majority of D10 Q705+-iPSC-PODs (arrow) were detected in the kidney tubulointerstitium (Figure 5D-E). However, on rare occasions, Q705+-iPSC-PODs (arrows) were found to localise within glomerular structures. No localisation of engrafted cells with podocytes was found.

\section{Discussion}

This article is protected by copyright. All rights reserved. 
This study provides evidence that differentiated iPSC-PODs are able to survive in recipient newborn mouse kidneys. Although engraftment was identified as a rare event under the current circumstances, we propose that newborn kidneys provide a supportive in vivo environment for cell transplantation due to the immature and immunoprivileged nature of the developing postnatal organs. We also report that iPSC-PODs may provide a valuable in vitro system for cell and disease modelling, and ultimately the isolation of kidney cells for replacement therapy. Following transplantation, differentiated iPSC-PODs were detected in newborn mouse kidneys in the renal cortex and interstitium as early as P2. The labelled iPSC-PODs were shown to localise adjacent to developing glomeruli in the nephrogenic zone using co-localisation with glomerular markers.

The reprogramming of adult cells to generate iPSCs may provide an unprecedented opportunity to elucidate disease mechanisms in vitro, for disease-modifying bioassays and to advance cellreplacement therapy. In order to use iPSC-derived kidney derivatives for cell replacement, numerous factors need to be considered, including the host-mediated immune response, posttransplanted cell differentiation and nephron (mesenchyme-to-epithelial) maturation, vascularisation, scalability and safety (Dekel et al., 2002; Harari-Steinberg, Pleniceanu, \& Dekel, 2011; Pleniceanu, Harari-Steinberg, \& Dekel, 2010; Sharmin et al., 2016; van den Berg et al., 2018). Previously, the engraftment of human fetal metanephroi has been shown following transplantation under the kidney capsule of rodents (Dekel et al., 2002). However, little is known about the fate of monolayer iPSC-derived kidney progenitor cells following transplantation in 
vivo, or renal progenitor cell survival and migration following delivery (Imberti et al., 2015; Toyohara et al., 2015). Imberti et al. (2015) demonstrated the integration of intravenous delivered iPSC-derived renal progenitor cells after 24 hours in the kidneys of mice with cisplatin-induced acute kidney injury. Moreover, using a mouse model of kidney ischemia reperfusion injury, Toyohara et al. (2015) suggested that the therapeutic effect following transplantation under the kidney capsule was mostly mediated from secreted trophic factors.

Here we provide evidence that heterogeneous iPSC-derived podocytes can be engrafted into newborn mouse kidneys following transplantation. Using Nphs1-GFP-iPSCs a variable expression of GFP+ protein was found following differentiation into kidney podocytes using fluorescent microscopy and qPCR (data not shown), and therefore the expression of nephrinGFP in vivo was not visible upon injection as opposed to the use of cell aggregate as previously reported (Sharmin et al., 2016). This may be due to insufficient slit diaphragm development or inadequate close proximity post injection to enable the formation of an adherens junction complex (Reiser, Kriz, Kretzler, \& Mundel, 2000). Additional cell trackers, including CFSE+ and Q705, were therefore used to provide proof of principle of the survival and incorporation of differentiated iPSC-POD in newborn mice. To improve the frequency of cell detection and integration into newborn kidneys, the use of selective injury models to induce podcocyte depletion, such as the dose inducible iDTR $+/ 2$;Pod-Cre+/2 transgenic mouse, could be used (Guo et al., 2012). Moreover, an integrin knockout mouse model (pod-Cre; $\beta 1$ flox/flox mice) 
that induces podocyte effacement has been reported in newborn mice up to P21 (Pozzi et al., 2008).

Mouse lineage studies have advanced the understanding of the origin of the kidney [see reviews: (Little, Hale, Howden, \& Kumar, 2019) and (Atsuhiro Taguchi \& Nishinakamura, 2015)]. This collective effort has enabled the directed differentiation of iPSC into three-dimensional kidney organoids, which includes the complex self-organisation of nephron progenitor cells and ureteric bud progenitor cells (Freedman et al., 2015; Morizane et al., 2015; A. Taguchi \& Nishinakamura, 2017; Takasato et al., 2015). The co-culturing of iPSC with mouse embryonic spinal cord has also been shown to induce tubulogenesis to produce an ureteric bud progenitor cell aggregate containing podocytes (Sharmin et al., 2016). Sharmin et al. (2016) transplanted these cell aggregates under the kidney capsule to assess nephron development and vascularisation. Consistent with previous literature (Dekel et al., 2002), the transplantation of human iPSCderived kidney organoids were found to vascularise in situ within the transplanted aggregate and promote nephron maturation (Bantounas et al., 2018; van den Berg et al., 2018).

The reasons for the difficulty in being able to identify single progenitor cells following transplantation into the kidney in vivo are multi-faceted. First of all, the kidney is a complex organ with over 20 different cell types, despite the organ being highly vascularised, which may be often perceived as an ideal target point for host recipients. Importantly, iPSC-derived cell progeny are generally small in size and difficult to detect for the purpose of transplantation 
(Davies \& Lawrence, 2018). To aid in cell tracing, an administration technique that allows siterestricted tracing, for example, subcapsular transplantation of cells/tissue into the kidney is available (Sharmin et al., 2016). However, tight space tension within the kidney is a limitation, which disrupts the viability of injected cells and hinders potential nephron formation (Sharmin et al., 2016). To overcome this challenge, the insertion of bioengineered devices, such as miniature agarose rods to limit tissue tension, has been reported (Sharmin et al., 2016). Alternatively, Atsuhiro Taguchi and Nishinakamura (2015) hypothesised that due to a lack of stroma cell support, transplanted iPSC nephron progenitor cell aggregates could promptly disintegrate following transplantation in vivo. A greater understanding of the differential gene expression, for example adhesion molecules and stromal cell signalling, in the host recipient tissue and transplanted cells would be useful to prolong cell survival and integration.

In this study we have used newborn mice to facilitate the detection of surviving iPSC-derived kidney cell derivatives which constitutes a receptive host environment as glomerulodevelopment is still ongoing (Hartman et al., 2007). In newborn mice, Six2+ cap mesenchyme cells have been found to reduce and exhaust shortly after birth (Short et al., 2014). Further highresolution global topography (Short et al., 2014) after transplantation may aid in the visualisation of transplanted cells and interaction within the host. There are technical challenges when using neonatal mice that are due to improper injection techniques and handling that amount to poor survivability due to infanticide of injected/wounded pups by stressed and agitated dams (Weber, Algers, Hultgren, \& Olsson, 2013). However, such study complications can be bypassed by cross 
fostering (Bartolomucci et al., 2004) or the introduction of a high protein diets into the litter. A good foster mother will increase pup survivability of the injected pups, although reduced handling of the pups is advised as the introduction of foreign smell can trigger infant cannibalism.

In the current study, we have developed a novel intrarenal injection technique for the delivery of cells into newborn mice to identify the fate of monolayer iPSC kidney derivatives. For up to one week, differentiated iPSC-POD, that expressed nephrin and podocin, were pre-labelled with live cell markers, CFSE and Qdot Q705, and were found in, or near to, the tubuloinstitium and nephrogenic zone in newborn mice. Transplanted iPSC-PODs were viable following delivery and engrafted in the outer nephrogenic zone where they co-localised with glomerular-specific markers including podocin, synaptopodin and WT1, in recipient newborn mice following direct intrarenal injection. 


\section{Acknowledgements}

The NPHS1-GFP hiPSC reporter cell line was a gift from Professor Ryuichi Nishinakamura,

Kumamoto University, Japan. The human immortalised podocytes were obtained from Professor

Moin A. Saleem, University of Bristol, UK.

\section{References}

Afkarian, M., Sachs, M. C., Kestenbaum, B., Hirsch, I. B., Tuttle, K. R., Himmelfarb, J., \& de Boer, I. H. (2013). Kidney disease and increased mortality risk in type 2 diabetes. $J$ Am Soc Nephrol, 24(2), 302-308. doi:10.1681/ASN.2012070718

Bantounas, I., Ranjzad, P., Tengku, F., Silajdžić, E., Forster, D., Asselin, M.-C., ... Wang, Q. (2018). Generation of functioning nephrons by implanting human pluripotent stem cellderived kidney progenitors. Stem Cell Reports, 10(3), 766-779.

Bartolomucci, A., Gioiosa, L., Chirieleison, A., Ceresini, G., Parmigiani, S., \& Palanza, P. (2004). Cross fostering in mice: behavioral and physiological carry - over effects in adulthood. Genes, Brain and Behavior, 3(2), 115-122.

Behr, L., Hekmati, M., Lucchini, A., Houcinet, K., Faussat, A. M., Borenstein, N., . . Laborde, K. (2009). Evaluation of the effect of autologous mesenchymal stem cell injection in a large-animal model of bilateral kidney ischaemia reperfusion injury. Cell Prolif, 42(3), 284-297. doi:10.1111/j.1365-2184.2009.00591.x

Davies, J. A., \& Lawrence, M. L. (2018). Chapter 14 - Four challenges for organoid engineers. In J. A. Davies \& M. L. Lawrence (Eds.), Organs and Organoids (pp. 255-259): Academic Press.

Dekel, B., Amariglio, N., Kaminski, N., Schwartz, A., Goshen, E., Arditti, F. D., . . Rechavi, G. (2002). Engraftment and differentiation of human metanephroi into functional mature nephrons after transplantation into mice is accompanied by a profile of gene expression

This article is protected by copyright. All rights reserved. 
similar to normal human kidney development. Journal of the American Society of Nephrology, 13(4), 977-990.

Freedman, B. S., Brooks, C. R., Lam, A. Q., Fu, H., Morizane, R., Agrawal, V., . . Bonventre, J. V. (2015). Modelling kidney disease with CRISPR-mutant kidney organoids derived from human pluripotent epiblast spheroids. Nat Commun, 6, 8715. doi:10.1038/ncomms9715

Garreta, E., Sanchez, S., Lajara, J., Montserrat, N., \& Belmonte, J. C. I. (2018). Roadblocks in the Path of iPSC to the Clinic. Current transplantation reports, 5(1), 14-18.

Guo, J. K., Marlier, A., Shi, H., Shan, A., Ardito, T. A., Du, Z. P., . . Cantley, L. G. (2012). Increased tubular proliferation as an adaptive response to glomerular albuminuria. $\mathrm{J} \mathrm{Am}$ Soc Nephrol, 23(3), 429-437. doi:10.1681/asn.2011040396

Harari-Steinberg, O., Pleniceanu, O., \& Dekel, B. (2011). Selecting the optimal cell for kidney regeneration: fetal, adult or reprogrammed stem cells. Organogenesis, 7(2), 123-134. doi:10.4161/org.7.2.15783

Hartman, H. A., Lai, H. L., \& Patterson, L. T. (2007). Cessation of renal morphogenesis in mice. Dev Biol, 310(2), 379-387. doi:10.1016/j.ydbio.2007.08.021

Huber, T. B., Kottgen, M., Schilling, B., Walz, G., \& Benzing, T. (2001). Interaction with podocin facilitates nephrin signaling. $J$ Biol Chem, 276(45), 41543-41546. doi:10.1074/jbc.C100452200

Imberti, B., Tomasoni, S., Ciampi, O., Pezzotta, A., Derosas, M., Xinaris, C., . . . Benigni, A. (2015). Renal progenitors derived from human iPSCs engraft and restore function in a mouse model of acute kidney injury. Scientific reports, 5, 8826.

Kunter, U., Rong, S., Djuric, Z., Boor, P., Müller-Newen, G., Yu, D., \& Floege, J. (2006). Transplanted Mesenchymal Stem Cells Accelerate Glomerular Healing in Experimental Glomerulonephritis. Journal of the American Society of Nephrology, 17(8), 2202-2212. doi:10.1681/asn.2005080815

Lam, A. Q., Freedman, B. S., \& Bonventre, J. V. (2014). Directed differentiation of pluripotent stem cells to kidney cells. Paper presented at the Seminars in nephrology.

Little, M. H., Hale, L. J., Howden, S. E., \& Kumar, S. V. (2019). Generating Kidney from Stem Cells. Annual review of physiology, 81, 335-357.

This article is protected by copyright. All rights reserved. 
McFetridge, M. L., Del Borgo, M. P., Aguilar, M.-I., \& Ricardo, S. D. (2018). The use of hydrogels for cell-based treatment of chronic kidney disease. Clinical Science, 132(17), 1977-1994.

Moghadasali, R., Azarnia, M., Hajinasrollah, M., Arghani, H., Nassiri, S. M., Molazem, M., .. . Aghdami, N. (2014). Intra-renal arterial injection of autologous bone marrow mesenchymal stromal cells ameliorates cisplatin-induced acute kidney injury in a rhesus Macaque mulatta monkey model. Cytotherapy, 16(6), 734-749. doi:10.1016/j.jcyt.2014.01.004

Morizane, R., Lam, A. Q., Freedman, B. S., Kishi, S., Valerius, M. T., \& Bonventre, J. V. (2015). Nephron organoids derived from human pluripotent stem cells model kidney development and injury. Nat Biotechnol, 33(11), 1193-1200. doi:10.1038/nbt.3392

Musah, S., Mammoto, A., Ferrante, T. C., Jeanty, S. S. F., Hirano-Kobayashi, M., Mammoto, T., . . Ingber, D. E. (2017). Mature induced-pluripotent-stem-cell-derived human podocytes reconstitute kidney glomerular-capillary-wall function on a chip. Nat Biomed Eng, 1. doi:10.1038/s41551-017-0069

Peired, A. J., Sisti, A., \& Romagnani, P. (2016). Mesenchymal Stem Cell-Based Therapy for Kidney Disease: A Review of Clinical Evidence. Stem cells international, 2016, 4798639-4798639. doi:10.1155/2016/4798639

Picollet-D’hahan, N., Dolega, M. E., Freida, D., Martin, D. K., \& Gidrol, X. (2017). Deciphering cell intrinsic properties: A key issue for robust organoid production. Trends in biotechnology, 35(11), 1035-1048.

Pleniceanu, O., Harari - Steinberg, O., \& Dekel, B. (2010). Concise review: kidney stem/progenitor cells: differentiate, sort out, or reprogram? Stem cells, 28(9), 1649-1660.

Pozzi, A., Jarad, G., Moeckel, G. W., Coffa, S., Zhang, X., Gewin, L., . . Zent, R. (2008). Beta1 integrin expression by podocytes is required to maintain glomerular structural integrity. Dev Biol, 316(2), 288-301. doi:10.1016/j.ydbio.2008.01.022

Quimby, J. M., Webb, T. L., Randall, E., Marolf, A., Valdes-Martinez, A., \& Dow, S. W. (2016). Assessment of intravenous adipose-derived allogeneic mesenchymal stem cells for the treatment of feline chronic kidney disease: a randomized, placebo-controlled clinical trial in eight cats. J Feline Med Surg, 18(2), 165-171. doi:10.1177/1098612x15576980

Reiser, J., Kriz, W., Kretzler, M., \& Mundel, P. (2000). The glomerular slit diaphragm is a modified adherens junction. J Am Soc Nephrol, 11(1), 1-8.

This article is protected by copyright. All rights reserved. 
Saleem, M. A., O'Hare, M. J., Reiser, J., Coward, R. J., Inward, C. D., Farren, T., . . Mundel, P. (2002). A conditionally immortalized human podocyte cell line demonstrating nephrin and podocin expression. J Am Soc Nephrol, 13(3), 630-638.

Sharmin, S., Taguchi, A., Kaku, Y., Yoshimura, Y., Ohmori, T., Sakuma, T., . . Nishinakamura, R. (2016). Human induced pluripotent stem cell-derived podocytes mature into vascularized glomeruli upon experimental transplantation. Journal of the American Society of Nephrology, 27(6), 1778-1791.

Short, K. M., Combes, A. N., Lefevre, J., Ju, A. L., Georgas, K. M., Lamberton, T., . . Little, M. H. (2014). Global quantification of tissue dynamics in the developing mouse kidney. Dev Cell, 29(2), 188-202. doi:10.1016/j.devcel.2014.02.017

Song, B., Smink, A. M., Jones, C. V., Callaghan, J. M., Firth, S. D., Bernard, C. A., . . Ricardo, S. D. (2012). The directed differentiation of human iPS cells into kidney podocytes. PloS one, 7(9), e46453.

Taguchi, A., \& Nishinakamura, R. (2015). Nephron reconstitution from pluripotent stem cells. Kidney international, 87(5), 894-900.

Taguchi, A., \& Nishinakamura, R. (2017). Higher-Order Kidney Organogenesis from Pluripotent Stem Cells. Cell stem cell, 21(6), 730-746.e736. doi:10.1016/j.stem.2017.10.011

Takahashi, K., Tanabe, K., Ohnuki, M., Narita, M., Ichisaka, T., Tomoda, K., \& Yamanaka, S. (2007). Induction of pluripotent stem cells from adult human fibroblasts by defined factors. cell, 131(5), 861-872.

Takasato, M., Er, P. X., Chiu, H. S., Maier, B., Baillie, G. J., Ferguson, C., . . . Little, M. H. (2015). Kidney organoids from human iPS cells contain multiple lineages and model human nephrogenesis. Nature, 526(7574), 564-568. doi:10.1038/nature15695

Toyohara, T., Mae, S.-I., Sueta, S.-I., Inoue, T., Yamagishi, Y., Kawamoto, T., . . Tanaka, H. (2015). Cell therapy using human induced pluripotent stem cell - derived renal progenitors ameliorates acute kidney injury in mice. Stem cells translational medicine, 4(9), 980-992.

Turner, P. V., Brabb, T., Pekow, C., \& Vasbinder, M. A. (2011). Administration of substances to laboratory animals: routes of administration and factors to consider. Journal of the American Association for Laboratory Animal Science : JAALAS, 50(5), 600-613. Retrieved from

This article is protected by copyright. All rights reserved. 
van den Berg, C. W., Ritsma, L., Avramut, M. C., Wiersma, L. E., van den Berg, B. M., Leuning, D. G., . . . Koster, A. J. (2018). Renal subcapsular transplantation of PSCderived kidney organoids induces neo-vasculogenesis and significant glomerular and tubular maturation in vivo. Stem Cell Reports, 10(3), 751-765.

Weber, E. M., Algers, B., Hultgren, J., \& Olsson, I. A. S. (2013). Pup mortality in laboratory mice--infanticide or not? Acta veterinaria Scandinavica, 55(1), 83-83. doi:10.1186/17510147-55-83

\section{FIGURE LEGENDS}

\section{Figure 1 - The differentiation of iPSCs into podocytes over 20 days of culture. (A).}

Diagrammatic representation of iPSCs derived from skin fibroblasts, embryonic stem cell-like colonies were observed. After the cells grew to 50-60\% confluency, iPSCs were differentiated into podocytes by the addition of three growth factors, namely activing A, BMP7 and retinoic acid for ten days. After 10 days (D10), the growth factors were removed. By D15 of culture, podocin and nephrin were observed on the cell surface of differentiated iPSC-PODs. (B). As compared to undifferentiated cells (D0), podocin, an intramembranous hairpin shaped protein specific to podocytes, was observed as early as D5. Differentiation of iPSCs into podocytes was confirmed with podocin expression over 20 days of culture, compared to D5 cultured IMMPODs. Magnification x200; ES - primate embryonic stem cell media; b-FGF - basic fibroblast growth factor; MEF - mouse embryonic fibroblast feeder layer; E8 - Essential 8 medium; DMEM/F12 - Dulbecco’s Modified Eagle Medium: Nutrient Mixture F-12; ActA - Activin A;

This article is protected by copyright. All rights reserved. 
BMP7 - bone morphogenetic protein 7; IMM-PODs - immortalised podocytes and RA - retinoic acid.

Figure 2 - Culturing of a reporter cell iPSC cell line, NPHS1-GFP-iPSCs, differentiation into podocytes and the characterisation using immunostaining. (A). NPHS1-GFP-iPSCs culture was compared on a feeder layer (left) and a commercially available non-feeder layer such as Geltrex ${ }^{\mathrm{TM}}$ (middle). Both colonies displayed embryonic stem cell-like morphology, including a high nuclear-to-cytoplasmic ratio with a low rate of spontaneous differentiation. Using the differentiation protocol outlined in Figure 1, the day 10 (D10) differentiated podocytes expressed nephrin-GFP protein, which was localised to the cell cytoplasmic region (right). Magnification x100 (B). NPHS1-GFP-iPSC-PODs co-expressed cytoplasmic GFP+ nephrin (white arrows) and podocyte markers: namely synaptopodin and WT1 at D10 and D15 as opposed to the negative control, IMM-PODs. NPHS1 - the gene encoding for nephrin protein; SYN - synaptopodin; WT1 - Wilms’ Tumour 1; IMM-PODs - immortalised podocytes. Magnification x200.

Figure 3 - Schematic diagram of the workflow to assess cell engraftment using a novel percutaneous intrarenal injection of labelled iPSC-PODs into postnatal mice. (A). D10 and D15 of NPHS1-GFP-iPSC-PODs were pre-labelled and injected intrarenally into C57BL/6J mice on P1. This timing of injection corresponded prior to potential cessation of nephrogenesis. The injected mice were killed 1 and 7 days post injection and the left kidneys were frozen for serial sectioning. The engraftment of both CFSE+ and Q705+ labelled cells integrated into host

This article is protected by copyright. All rights reserved. 
kidneys was examined. (B). A firm but gentle pressure between the thumb and the index finger allowed for visualisation of the bulging kidney near the left mid-line of the animal. (C). $10 \mu$ l of cells in diluent was injected into the left kidney (white arrow) using a 29G syringe at an acute angle to the mid-line of the animal body.

Figure 4 - Visualisation of transplanted CFSE+-iPSC-PODs in host kidneys. (A). Initial tracing of CFSE+ cells showed that the injection of D10 CFSE+-iPSC-PODs integrated into newborn kidneys. (B-D). Under widefield low magnification, D10 CFSE+-iPSC-PODs were found to localise near or adjacent to cells expressing synaptopodin+, podocin+, and WT1+ in both the tubulointerstitium and glomerular region. Magnification $\mathrm{x} 400$; scale bar $=50 \mu \mathrm{m}$. (E). Confocal images under high magnification showed that D10 CFSE+-iPSC-PODs integrated into developing glomeruli at the capillary loop stage. Glomeruli at high magnification with the SYN+CFSE+DAPI and POD+CFSE+DAPI co-localised images. SYN - synaptopodin; POD podocin; WT1 - Wilms' Tumour 1 . Scale bar $=5 \mu \mathrm{M}$.

Figure 5 - Engraftment into host newborn kidneys was assessed by the visualisation of Q705 labelled vesicles in transplanted cells. (A). Qdot nanocrystal (red), used to track transplanted D10 iPSC-PODs, was observed in newborn mouse kidneys at P2. Magnification x200; (B). Q705+ vesicles (cyan, white arrows) were found in the subcapsular nephrogenic zone of newborn kidneys and in s-shaped bodies of developing kidneys postnatally (C). The morphology of Q705+ vesicles co-localised with DAPI at higher magnification was shown demonstrating

This article is protected by copyright. All rights reserved. 
human cells were transplanted into the mouse host. (D). At P8, D10 Q705+-iPSC-PODs (arrow) were also found to localise adjacent to cells expressing WT1+ in the tubulointerstitium. Magnification $\mathrm{x} 400$; Scale bar $=100 \mu \mathrm{M}$. (E). After one week post injection, Q705+-iPSC-PODs (arrow) were found within glomerular structures, although not co-localised with podocin expression. Magnification $\mathrm{x} 400$; Scale bar $=100 \mu \mathrm{M}$. Also shown at high magnification $(\mathrm{F})$, scale bar $=20 \mu \mathrm{M}$.

This article is protected by copyright. All rights reserved. 


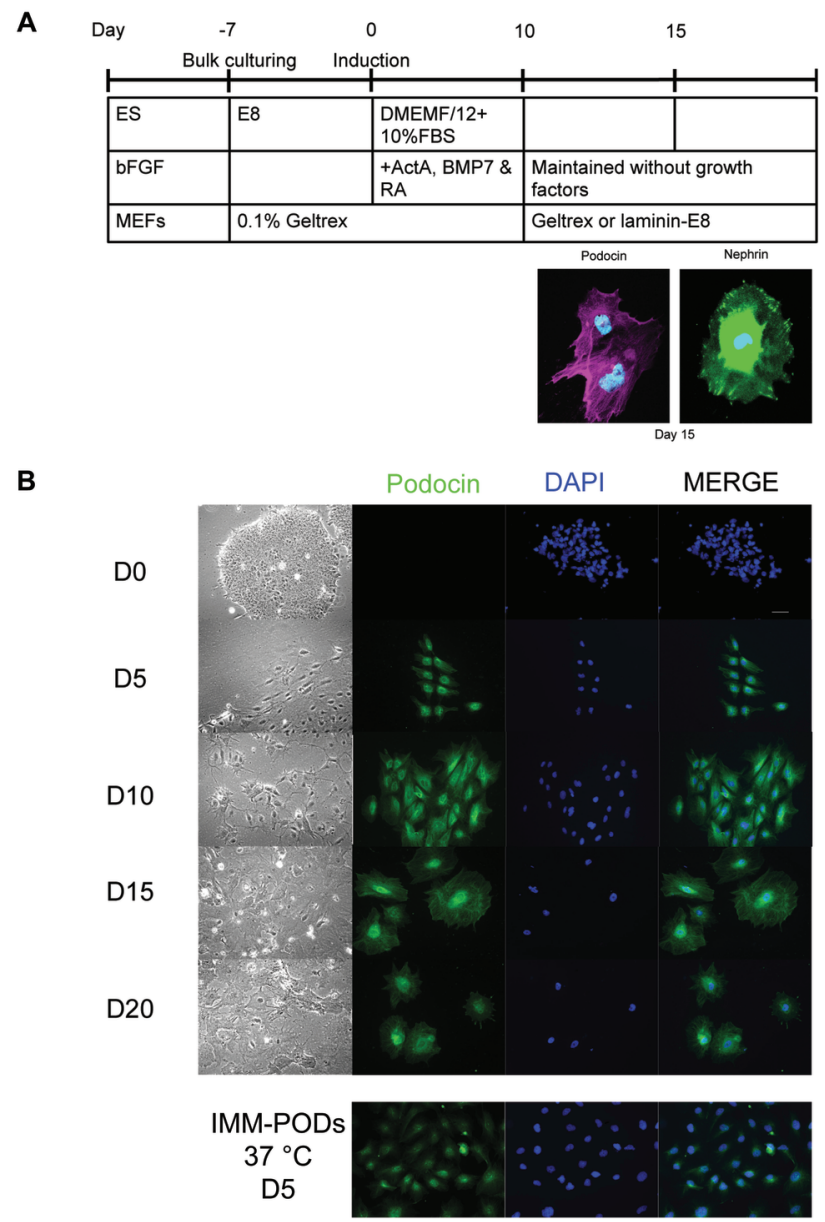

AR_24371_Lau et al., Fig 1.tif

This article is protected by copyright. All rights reserved. 


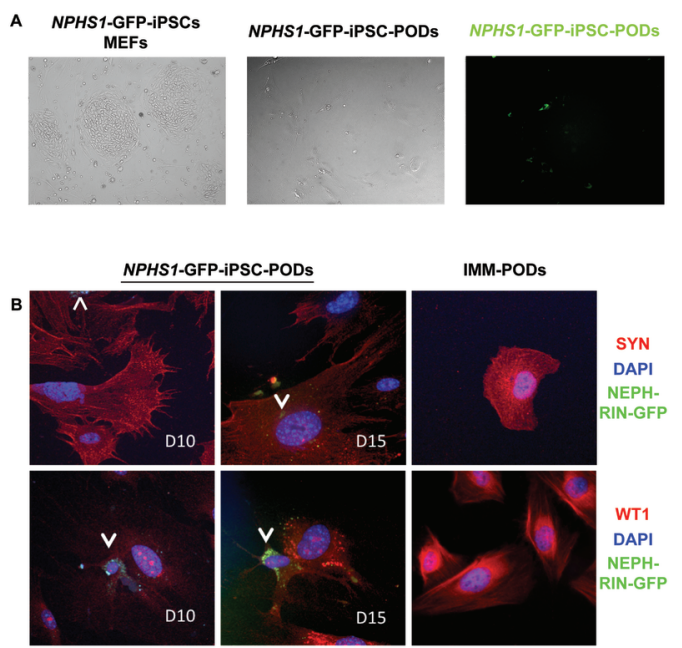

AR_24371_Lau et al., Fig 2 copy.tif

This article is protected by copyright. All rights reserved. 

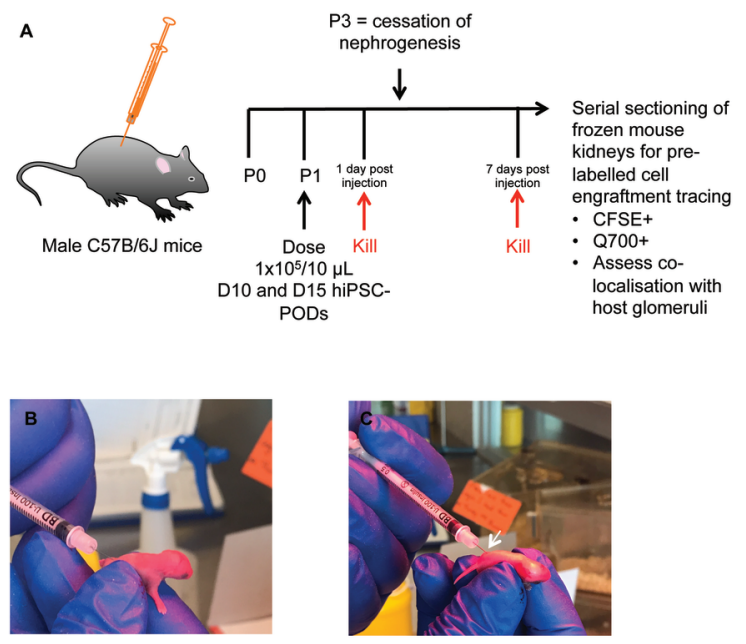

AR_24371_Lau et al., Fig 3.tif

This article is protected by copyright. All rights reserved. 


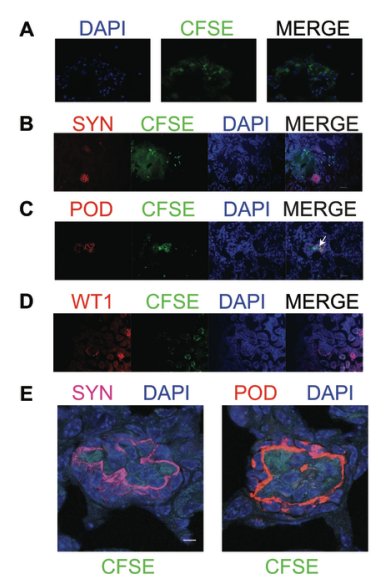

AR_24371_Lau et al., Fig 4.tif

This article is protected by copyright. All rights reserved. 

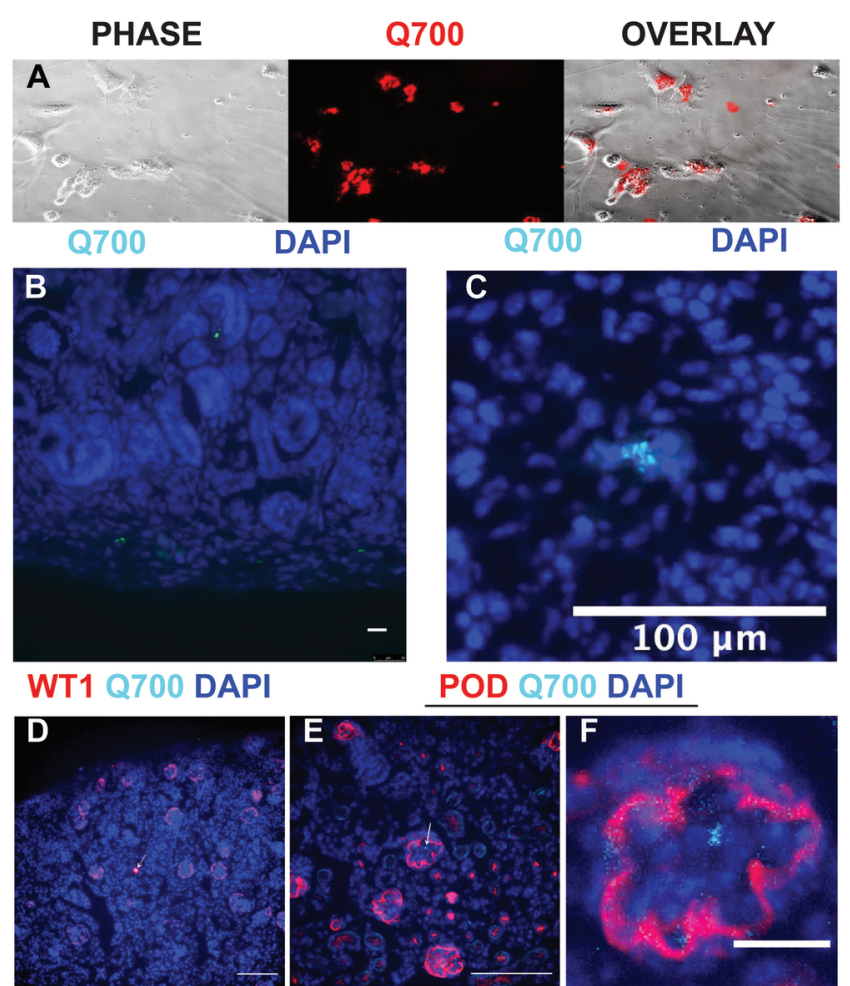

AR_24371_Lau et al., Fig 5.tif

This article is protected by copyright. All rights reserved. 


\section{University Library}

\section{- M M N E R VA A gateway to Melbourne's research publications}

Minerva Access is the Institutional Repository of The University of Melbourne

Author/s:

Lau, RWK;Al-Rubaie, A;Saini, S;Wise, AF;Ricardo, SD

Title:

Percutaneous intrarenal transplantation of differentiated induced pluripotent stem cells into newborn mice.

Date:

2020-10

Citation:

Lau, R. W. K., Al-Rubaie, A., Saini, S., Wise, A. F. \& Ricardo, S. D. (2020). Percutaneous intrarenal transplantation of differentiated induced pluripotent stem cells into newborn mice.. Anat Rec (Hoboken), 303 (10), pp.2603-2612. https://doi.org/10.1002/ar.24371.

Persistent Link:

http://hdl.handle.net/11343/275393 